\title{
Functional implications of age differences in motor system connectivity
}

\author{
Jeanne Langan ${ }^{1,2}$, Scott J. Peltier ${ }^{3}$, Jin Bo ${ }^{1}$, Brett W. Fling ${ }^{1,2}$, Robert C. Welsh ${ }^{4,5}$ and Rachael D. Seidler ${ }^{1,2,6 *}$ \\ ISchool of Kinesiology, University of Michigan, Ann Arbor, MI, USA \\ 2 Department of Biomedical Engineering, University of Michigan, Ann Arbor, MI, USA \\ ${ }^{3}$ Department of Psychology, University of Michigan, Ann Arbor, MI, USA \\ 4 Institute of Gerontology, University of Michigan, Ann Arbor, MI, USA \\ ${ }^{5}$ Department of Radiology, University of Michigan, Ann Arbor, MI, USA \\ ${ }^{6}$ Department of Psychiatry, University of Michigan, Ann Arbor, MI, USA
}

Edited by:

Lucina Q. Uddin,

Stanford University, USA

\section{Reviewed by:}

Martijn van den Heuvel,

Universitair Medisch Centrum Utrecht,

Netherlands

Christophe Habas,

Université Pierre et Marie Curie, France

${ }^{*}$ Correspondence:

Rachael D. Seidler,

Department of Psychology and School of Kinesiology, University of Michigan, 401 Washtenaw Avenue, Ann Arbor, Ml 48109-2214, USA

e-mail: rseidler@umich.edu
Older adults show less lateralized task-related brain activity than young adults. One potential mechanism of this increased activation is that age-related degeneration of the corpus callosum (CC) may alter the balance of inhibition between the two hemispheres. To determine whether age differences in interhemispheric connectivity affect functional brain activity in older adults, we used magnetic resonance imaging (MRI) to assess resting functional connectivity and functional activation during a simple motor task. We found that older adults had smaller CC area compared to young adults. Older adults exhibited greater recruitment of ipsilateral primary motor cortex (M1), which was associated with longer reaction times. Additionally, recruitment of ipsilateral M1 in older adults was correlated with reduced resting interhemispheric connectivity and a larger CC. We suggest that reduced interhemispheric connectivity reflects a loss of the ability to inhibit the non-dominant hemisphere during motor task performance for older adults, which has a negative impact on performance.

Keywords: aging, corpus callosum, fMRI, functional connectivity, motor cortex

\section{INTRODUCTION}

Older adults have been shown to recruit more of the brain than young adults to perform a given task. The hemispheric asymmetry reduction in older adults (HAROLD) model characterizes this phenomenon in cognitive tasks (Cabeza, 2001). It describes the finding that older adults typically have less lateralized prefrontal cortex recruitment than younger adults during the performance of cognitive tasks (cf. Reuter-Lorenz and Lustig, 2005). Similarly, older adults performing motor tasks tend to recruit more brain regions compared to young adults, particularly the primary motor cortex (M1) ipsilateral to the moving limb (Mattay et al., 2002; Ward and Frackowiak, 2003; Heuninckx et al., 2005, 2008; Riecker et al., 2006).

The recruitment of additional brain regions by older adults has been associated with enhanced performance of both cognitive (Reuter-Lorenz et al., 2000; Cabeza et al., 2002) and motor tasks (Mattay et al., 2002; Heuninckx et al., 2008), suggesting that increased activation in older adults serves a compensatory purpose. In contrast, there are examples of older adults demonstrating greater activation yet exhibiting diminished (Madden et al., 1999) or similar performance to young adults (Hutchinson et al., 2002). Thus, over-activation may also reflect nonspecific activity or dedifferentiation (Li et al., 2001; Li and Sikstrom, 2002; for a review see Seidler et al., 2010).

Ipsilateral motor activation in older adults may be the result of structural decline of the corpus callosum (CC), possibly leading to recruitment of the ipsilateral cortex via interhemispheric motor overflow. The CC is the primary means of communication between hemispheres. Unimanual movement of the dominant hand has a net inhibitory effect on the ipsilateral M1 (Sohn et al., 2003; Vercauteren et al., 2008). The reduced CC integrity that accompanies aging (Sullivan et al., 2002; Head et al., 2004) may disrupt interhemispheric balance; indeed, older adults demonstrate reduced inhibition between hemispheres compared to young adults (Talelli et al., 2008a,b). As callosal connections between the two motor cortices appear to have a net inhibitory effect (Ferbert et al., 1992; Netz, 1999; De Gennaro et al., 2004; Duque et al., 2007), callosal degeneration with age may lead to greater activation of the ipsilateral M1 (due to reduced inhibition from the contralateral M1) during motor task performance. However, a complete section of the CC leads to an absence of ipsilateral activation during tactile stimulation (Fabri et al., 1999), suggesting that the relationship between CC integrity and ipsilateral activation in sensorimotor tasks may be nonlinear. Therefore, while some degeneration of the CC may lead to less lateralized task processing (Muller-Oehring et al., 2007), extensive damage or complete section of the CC would likely abolish ipsilateral activation.

Motor task difficulty has also been shown to have an impact on recruitment of ipsilateral M1. More complex motor tasks result in greater recruitment of brain regions, particularly the ipsilateral M1 (Seidler et al., 2004; Verstynen et al., 2005). This raises the question of whether ipsilateral M1 activity in older adults is due to age differences in task difficulty. Advances in imaging analyses, such as resting state functional connectivity (fcMRI), provide a way to assess communication between cortical regions without incorporating a task.

Regions with similar functions and known anatomical connections have shown strong correlations in the low-frequency blood oxygen level dependent (BOLD) signal, commonly referred to as 
fcMRI (Fox and Raichle, 2007; Rogers et al., 2007; Vincent et al., 2007). Examples of functional connectivity of anatomical regions with structural connections between hemispheres include motor networks (Biswal et al., 1995; Xiong et al., 1999; De Luca et al., 2005), visual networks (Lowe et al., 1998; Cordes et al., 2000) and auditory networks (Cordes et al., 2000). Moreover, resting state connectivity networks exhibit stability across data sets collected from different participants using differing acquisition parameters, locations, and scanners (Biswal et al., 2010). Recently, Lowe et al. (2008) found that measures of callosal integrity correlate with M1 interhemispheric resting state connectivity in patients with multiple sclerosis. Similarly, correlations between M1 in each hemisphere are greatly diminished with CC agenesis (Quigley et al., 2003) or callosal sectioning (Johnston et al., 2008). Taken together these data support that fcMRI is a noninvasive and reliable method for assessing resting state interhemsipheric connectivity.

The goal of the current study was to examine the influence of age differences in interhemispheric connectivity upon brain activation patterns and task performance in older adults. We used a region of interest (ROI) approach (cf. Peltier et al., 2005; Di Martino et al., 2008) to compare resting state connectivity between the two M1s. We hypothesized that: 1. M1 task-related fMRI activation in older adults would be less lateralized, with increased activation serving a compensatory role; 2 . Older adults would have smaller CCs and greater M1 resting interhemispheric connectivity; and 3. Older adults demonstrating stronger $\mathrm{M} 1$ resting interhemispheric connectivity would demonstrate less laterality in M1 task-related fMRI activation.

\section{MATERIALS AND METHODS PARTICIPANTS AND PROCEDURE}

Young ( $n=18,21.4 \pm 2.1$ years, nine males) and older ( $n=18$, $71.7 \pm 5.8$ years, nine males) adults were recruited from the University of Michigan community and through the University of Michigan National Institutes of Health Claude D. Pepper Older American's Independence Center human subjects and assessment core. All participants signed an internal review board approved consent form prior to entrance into the study. Participants were free of contraindications for an fMRI study as determined by a health questionnaire and were right handed, as verified by the Edinburgh Handedness Inventory (Oldfield, 1971, young adult's mean $=77 \pm 14$, older adult's mean $=89 \pm 10, t=2.81, \mathrm{df}=32$, $p=0.01)$. Cognitive status was assessed using the Mini Mental Status Examination (minimum inclusion score 27/30, Folstein et al., 1975) and the Mattis Dementia Rating Scale (minimum inclusion score 124/144, Mattis, 1976). Screening occurred on the first of two testing days.

On day one of testing, participants were accepted into the study if they met the above inclusion criteria. They then practiced a motor task using their right (dominant) hand in a mock MRI scanner. Participants were comfortably positioned in the mock scanner with a mirror adjusted to allow visualization of a video screen. A dual potentiometer joystick was used to control the movement of a cursor on the screen. The starting position of the cursor was centered on the screen. Targets would appear randomly above, below, right, or left of the original cursor position. Participants were instructed to move the cursor as quickly and accurately as possible to the target, hold the cursor in the target until the target disappeared and then release the spring-loaded joystick allowing the cursor to return to the original centered position. Real-time feedback of the joystick location was presented as a cursor moving on the display screen. A trial was defined as the time between the appearance and disappearance of the target $(2.5 \mathrm{~s})$. The inter-trial interval was $2.5 \mathrm{~s}$. In a single run participants performed two blocks of 12 trials $(20 \mathrm{~s}$ visual fixation, block of 12 trials, $20 \mathrm{~s}$ visual fixation, block of 12 trials, $22 \mathrm{~s}$ visual fixation). Participants practiced three runs of the task in the mock scanner to become familiar with the operation of the joystick device and visual feedback display.

The second day of testing was conducted at the University of Michigan Functional MRI Laboratory. A series of scans were performed using a 3.0 T MRI scanner (General Electric, Waukesha, WI, USA). Participants' heads were comfortably restrained to reduce head movement. They wore fMRI compatible mirrored glasses to view a screen for the visual stimuli. During the first scan, which was collected for resting state functional connectivity analyses (fcMRI), participants gazed at a fixation cross. In total, 400 images were acquired in a time span of 5 min using a single-shot gradient-echo reverse-spiral pulse sequence. The repetition time (TR) was $750 \mathrm{~ms}$, echo time (TE) was $30 \mathrm{~ms}$, flip angle (FA) was 50 and field of view (FOV) was $220 \mathrm{~mm}$. Sixteen contiguous, 3.2-mm axial slices were acquired in each TR. Voxel size was $3.4-\mathrm{mm} \times 3.4 \mathrm{~mm} \times 3.2 \mathrm{~mm}$. These acquisition parameters result in lower signal to noise ratio than the task acquisition parameters (see below), but they allow us to (a) sample at a faster rate (as opposed to TR of 2), so that we have both increased degrees of freedom after the low-pass filter, and less chance of high frequency physiological noise aliasing into our frequency band of interest; and (b) acquire 400 samples in $5 \mathrm{~min}$, as opposed to only 150 samples with a $2 \mathrm{~s}$ TR. It would have taken over 13 min to acquire 400 samples with a $2 \mathrm{~s}$ TR, which was considered prohibitive given the older population being studied. Cardiac (measured with pulse oximeter) and respiratory (measured with chest plethysmography) signals were acquired for use in the data analyses.

During the motor task fMRI scans, participants performed two runs of the joystick task as previously described using their right hand. A single-shot gradient-echo reverse-spiral pulse sequence was also used to acquire the fMRI data. Pulse sequence parameters were TR/TE/FA/FOV of $2000 \mathrm{~ms} / 30 \mathrm{~ms} / 80 / 220 \mathrm{~mm}$ respectively. Forty, 3.2-mm-thick slightly oblique axial slices (no gap) were acquired. A total of 91 images were acquired, with each run lasting $182 \mathrm{~s}$. High-resolution anatomical images were also acquired using a $\mathrm{T} 1$-weighted gradient-echo pulse sequence with the following parameters: TR/TE/FA/FOV $200 \mathrm{~ms} / 3.7 \mathrm{~ms} / 90 / 220 \mathrm{~mm}$ and a voxel size of $1 \mathrm{~mm} \times 1 \mathrm{~mm} \times 1.2 \mathrm{~mm}$.

\section{BEHAVIORAL DATA ANALYSIS}

Custom Labview 6.1 software (National Instruments) was used to analyze the joystick data offline. A dual pass Butterworth digital filter (Winter 1990) using a cutoff frequency of $10 \mathrm{~Hz}$ was used to filter the raw data. The resultant joystick path was calculated by computing the square root of the sum of the squared X and Y coordinate data at each time point. The tangential velocity profile was then calculated through differentiation. The optimal algorithm of Teasdale (Teasdale et al., 1993) was used to determine move- 
ment onset and offset. Performance on the task was measured by reaction time (RT), initial endpoint error (IEE), and final endpoint error (FEE). RT was calculated by subtracting the time of the target presentation from the time of the movement onset. IEE represents the distance from the joystick controlled cursor and the target at the end of the first ballistic movement. The algorithm used to calculate IEE identifies a period of acceleration following a period of deceleration or a change in the sign of the velocity. FEE is the distance from the target at movement offset.

\section{MRI DATA ANALYSIS \\ fMRI data}

The first three volumes per run were discarded to allow for signal equilibration. High-pass filtering was used to remove low-frequency drift. Motion correction was performed using MCFLIRT and the brain extraction tool (BET) was used to strip the skull from images (using FSL toolboxes, http://www.fmrib.ox.ac.uk/fsl). Statistical Parametric Mapping version 5 (SPM5: www.fil.ion.ucl.ac.uk/spm/ software/spm5/) was used for subsequent analyses. A mean functional image was created for each participant. All functional and structural images were aligned to this mean functional image. The Montreal Neurological Institute (MNI) template was used for spatial normalization (Mazziotta et al., 1995). The structural image was normalized to MNI space first and the resulting parameters were applied to the functional images. Functional images were spatially smoothed using a full width at half-maximum 8-mm Gaussian smoothing kernel. Boxcar models synchronized to the effect of interest and convolved with an estimate of the hemodynamic response function were used for statistical analyses. A general linear model analysis was first conducted at an individual level across runs contrasting periods of movement with rest. The first level statistics were used to identify the MNI coordinates with the most significant activations in the hand knob region of the left primary M1 in each individual for the fcMRI analysis (see description below). Also at the first level, percent signal change for the motor task relative to the rest periods was calculated and averaged across runs. Second level random effects analyses were run for single group whole brain (uncorrected $p=0.0001$ ), and ROI analyses in the right primary somatosensory cortex and M1 (sensorimotor cortex, uncorrected $p=0.005)$. Between group analyses were also run for whole brain (uncorrected $p=0.001$ ) and ROI analyses in the right sensorimotor cortex (uncorrected $p=0.005$ ).

\section{fcMRI data}

The first 10 volumes were discarded to allow the signal to reach a steady state. Motion correction and the use of BET were the same as described for fMRI. Second-order harmonics of the simultaneously recorded cardiac and respiratory signals were regressed out in image space using RETROICOR (Glover et al., 2000). Linear trends were removed from the data to eliminate the effect of gross signal drifts. Low-pass filtering was performed with a cut-off frequency of $0.08 \mathrm{~Hz}$. No other temporal or spatial smoothing was performed on the fcMRI data. The hand knob region of the left M1 was identified visually for each subject. The hand knob has a distinct omega shape making it a good anatomical landmark (Yousry et al., 1997). In each individual the most active region in their hand knob during the fMRI task served as their seed for the fcMRI ROI analysis. The seed consisted of four neighboring voxels. The time courses from each of the four voxels in the seed region were averaged together to create one representative time course characterizing signal changes in the seed region over the length of the scan. Then, a correlation analysis between this representative time course of the seed region and all other voxels in the brain was performed. The degree of connectivity was quantified for each individual by calculating the average $z$ score of all suprathreshold voxels in the resting state correlation map $(p<0.05$, cluster threshold $>9$ contiguous voxels). In performing significance calculations, the degrees of freedom were decreased to reflect the reduced number of degrees of freedom in the low-pass filtered data.

The SPM toolbox WFU_Pickatlas (Maldjian et al., 2003) was used to define M1 and the primary somatosensory cortex. We combined these two regions of interest to create a sensorimotor cortex mask. The sensorimotor cortex mask was refined to reflect the cortex in common with all participants. Two older adults were removed from the analyses as their head position in the 16 slice fcMRI acquisition remarkably reduced the size of the sensorimotor cortex mask. The sensorimotor cortex mask was used as a ROI to calculate the percent signal change in suprathreshold voxels ( $p>0.001$ uncorrected, cluster threshold $>9$ contiguous voxels) in the task related fMRI data for each participant. In the fcMRI data the mask delineated the $z$ scores used to calculate a metric reflecting interhemispheric balance between the seed region in the left $\mathrm{M} 1$ and the right sensorimotor cortex for each participant. Figure 1 illustrates the time course of the seed region in the left hemisphere and the time course of a suprathreshold voxel in the right sensorimotor cortex for one representative participant. The correlation between these two time courses denotes functional interhemispheric connectivity. Correlations between the seed region and the right sensorimotor cortex will be referred to as sensorimotor cortex interhemispheric connectivity. In the group analyses using the right sensorimotor cortex mask the cluster threshold was $>4$ contiguous voxels for both fMRI and fcMRI data. To determine the degree of laterality in fMRI activation, a laterality index using the percent signal change in the sensorimotor cortex was calculated with the following formula: laterality index $=($ left sensorimotor cortex - right sensorimotor

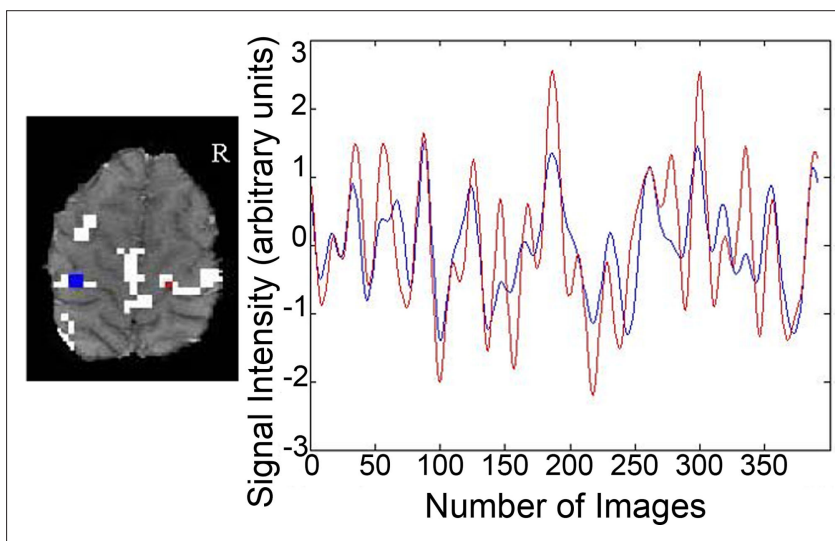

FIGURE 1 | Connectivity data from a representative participant. The seed region and corresponding time course for a single participant are depicted in blue. Voxels having correlation strength above threshold are shown in white. The time course for a suprathreshold voxel and the corresponding voxel are shown in red. 
cortex $) /(\text { left sensorimotor cortex }+ \text { right sensorimotor cortex })^{\star} 100$. A score of 100 would reflect complete lateralization to the left side. Conversely, a score of -100 would indicate complete lateralization to the right side.

\section{Anatomical data-CC morphology}

A custom Matlab program (MATLAB, MathWorks Inc. R2007b) was used to manually outline the CC from a mid-sagittal slice taken of a high-resolution T1 image. Another custom MATLAB program was then used to divide the CC into seven sub-regions as previously described by Witelson (1989). Individual variation in the size of these sections has been shown to relate to brain functional activity during sensory and motor processing (Stancak et al., 2002, 2003a,b) as well as correlations with the laterality of task processing in older adults (Muller-Oehring et al., 2007). In the Witelson scheme, the $\mathrm{CC}$ is separated into seven regions to roughly correspond to distinct anatomical connections of the caudal/orbital prefrontal, inferior premotor cortices (region 1), prefrontal cortices (2), premotor and supplementary motor areas (3), primary motor cortices (4), primary sensory cortices (5), superior temporal and posterior parietal cortices (6) and occipital, inferior temporal cortices (7) (Figure 2). However, it should be noted that these subdivisions were originally based upon anatomical work conducted in monkeys. More recent DTI tractography data from humans indicates that these regions, particularly 3-6, may be shifted posteriorly in the CC (Hofer and Frahm, 2006; Wahl et al., 2007; Bartels et al., 2008). Wahl et al. (2007) suggest that this posterior shift, particularly noted in callosal motor fibers, may be due to the significantly larger prefrontal cortex volume in humans as compared to monkeys (Eccles, 1989). Therefore, when considering our results, it is appropriate to consider fibers passing through CC regions 3-6 as connecting primary motor (5/6), premotor (3/4), and supplementary motor $(3 / 4)$ regions of the two hemispheres. Boundaries indicating the anteriormost (ACC) and posteriormost (PCC) border define the length of the CC (ACC-PCC line, Figure 2). The genu line, perpendicular

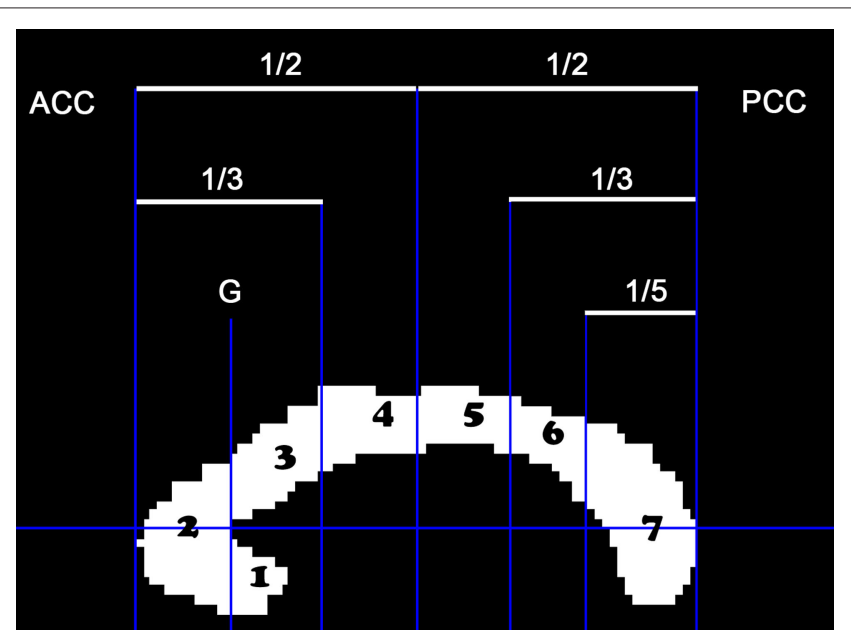

FIGURE 2 |The cross-sectional area of the mid-sagittal CC was parsed into seven regions: (1) rostrum, (2) genu, (3) rostral truncus, (4) anterior intermediate truncus, (5) posterior intermediate truncus, (6) isthmus, (7) splenium. to the ACC-PCC line, was placed at the anteriormost point of the inner convexity of the anterior CC defining regions 1 (rostrum) and 2 (genu). All other regions are defined as a proportion of the CC (see Figure 2). Cross-sectional area was calculated for each of the seven sub-regions. Three independent raters performed all steps to ensure CC measurements were reliable. The mean value of the raters was used in the analyses.

Intracranial area was also calculated for each subject utilizing the same custom MATLAB programs. The same mid-sagittal slice was used to measure the CC area and intracranial area for each subject. An outline was drawn along the interior border of the skull with a straight line connecting the nasion and the inion. The cross-sectional area of each CC sub-region was normalized to intracranial area to control for any atrophy and/or degeneration that may have occurred in the brains of our older adult participants. Two independent raters performed intracranial area measurements to establish reliability. The mean value of the raters was used in the analyses.

\section{STATISTICAL ANALYSES}

Statistical analyses were conducted in SPSS. Between group differences were analyzed using independent $t$ tests. Correlations were assessed between the sensorimotor cortex interhemispheric connectivity, percent signal change in the right sensorimotor cortex, fMRI laterality index, the motor performance variables, and fMRI activation peaks resulting from the contrast of older adults $>$ young adults. Scores that were outside 2.5 standard deviations from the mean for the group were excluded from the analyses. Inter-rater reliability for CC and intracranial area measurements was assessed with Krippendorff's alpha (Hayes and Krippendorff, 2007).

\section{RESULTS}

\section{BEHAVIORAL RESULTS}

Older adults did not perform at the same level as young adults on the motor task (Table 1); they took longer to initiate movements, moved more slowly during the initial ballistic movement towards the target, and ended the movement further from the target.

\section{MOTOR TASK-RELATED FMRI RESULTS}

The young adults and older adults recruited overlapping brain regions while performing the motor task, primarily in motor regions such as the bilateral precentral gyrus, left postcentral gyrus, right inferior and superior parietal lobe, and cerebellum. There were no regions where young adults showed greater activation

Table 1 | Older adults did not perform at the same level as young adults (all variables significantly different between the two age groups at $p<0.01$ ).

\begin{tabular}{lcc}
\hline Variable & YA & OA \\
\hline RT $(\mathrm{ms})$ & $481 \pm 100$ & $622 \pm 154$ \\
IEE $(\mathrm{mm})$ & $10.78 \pm 1.06$ & $19.43 \pm 1.43$ \\
PSMT $(\mathrm{ms})$ & $484 \pm 67$ & $599 \pm 98$ \\
FEE $(\mathrm{mm})$ & $6.79 \pm 1.08$ & $12.81 \pm 4.69$ \\
\hline
\end{tabular}

$R T$, reaction time; IEE, initial endpoint error; PSMT, primary submovement time; FEE, final endpoint error. 
than older adults. Similar to previous studies, older adults showed greater activation compared to young adults in many brain regions (Table 2); of particular interest to the current study is the right (ipsilateral) sensorimotor cortex. Figure 3 illustrates regions where older adults had greater activation within the right sensorimotor cortex ROI than the young adults (see also Table 3 ). There were no regions in the right sensorimotor cortex ROI analysis where young adults demonstrated greater activation compared to older adults.

Only older adults demonstrated a statistically significant correlation between percent signal change in the right sensorimotor cortex and motor behavior. Older adults that had longer RTs demonstrated more activation in the right sensorimotor cortex $(\mathrm{df}=14, r=0.57$, $p=0.02$, Figure 4). We did not find statistically significant correlations between fMRI measurements and IEE or FEE. Although not significant, the correlation between percent signal change in the right sensorimotor cortex and FEE ( $\mathrm{df}=13 r=0.41, p=0.13)$ in older adults suggests that kinematic performance may also be negatively impacted by increased activation in the right sensorimotor cortex.

\section{RESTING STATE fcMRI RESULTS}

Young and older adults demonstrated resting state connectivity between the left M1 seed region and some similar brain regions such as the left sensorimotor cortex, supplementary motor area, and bilateral parietal regions. There are few regions in which the young

Table 2 | Regions in which older adults exhibit more fMRI task-related activation than young adults (uncorrected $p=0.001$, whole brain analysis).

\begin{tabular}{lllll}
\hline Anatomical location & BA & $\begin{array}{l}\text { Cluster } \\
\text { size }\end{array}$ & $\begin{array}{l}\text { Coordinates } \\
\text { of peaks }\end{array}$ & z score \\
\hline FRONTAL AREAS & & & & \\
\hline L Superior frontal gyrus & 9 & 79 & -384230 & 3.9 \\
L Middle frontal gyrus & 8 & & -363440 & 3.38 \\
L Precentral gyrus & 6 & 23 & $-40-1242$ & 3.62 \\
R Medial frontal gyrus & 9 & 25 & 163830 & 3.58 \\
R Middle frontal gyrus & 10 & 27 & 385022 & 3.36 \\
R Middle frontal gyrus & 46 & 39 & 462626 & 3.34 \\
L Inferior frontal gyrus & 44 & 36 & -361028 & 3.31 \\
L Middle frontal gyrus & 9 & & -301034 & 3.15 \\
TEMPORAL AREAS & & & & \\
R Middle temporal gyrus & 21 & 136 & $420-22$ & 3.85 \\
PARIETAL AREAS & & & & \\
R Precuneus & 7 & 805 & $12-5646$ & 4.54 \\
L Precuneus & 7 & & $-2-5052$ & 3.99 \\
R Precuneus & 7 & & $12-4844$ & 3.97 \\
R Cuneus & 19 & & $20-8434$ & 3.37 \\
R Postcentral gyrus & 1 & 34 & $40-2046$ & 3.31 \\
R Postcentral gyrus & 3 & & $50-1244$ & 3.22 \\
R Fusiform gyrus & 37 & 10 & $34-44-14$ & 3.45 \\
SUBCORTICAL AREAS & & & & \\
\hline L Cerebellum (HIII) & & 70 & $-12-34-22$ & 4.59 \\
L Cerebellum (Crus I) & & 59 & $30-70-30$ & 3.97 \\
L Cerebellum (Crus I) & & 15 & $-22-72-36$ & 3.4 \\
\hline
\end{tabular}

$B A$, Brodmann's area; $L$, left; $R$, right. adults demonstrated statistically greater connectivity than the older adults (Figure 5A). In contrast, the older adults showed greater connectivity than the young adults in several right hemisphere regions (Figure 5B). Figure 6 presents the results of the right sensorimotor cortex ROI analysis. Older adults show stronger regions

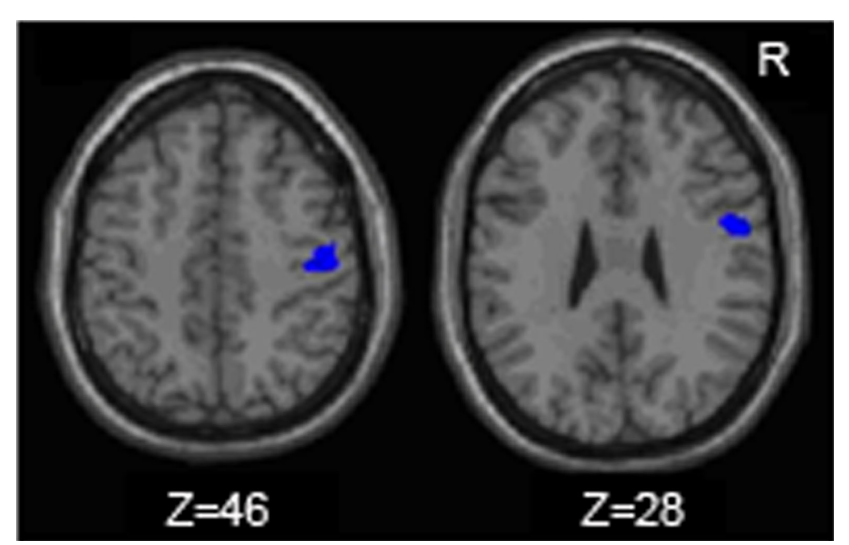

FIGURE 3 | Regions within the sensorimtor cortex ROI in which the older adults exhibited more motor task related activation (fMRI) than the young adults.

Table 3 | Regions in which older adults exhibit more fMRI task-related activation than young adults within the right sensorimotor cortex ROI (uncorrected $\boldsymbol{p}=\mathbf{0 . 0 0 5}$ ).

Anatomical location BA Cluster size Coordinate of peaks z score

\begin{tabular}{lcccc}
\hline FRONTAL AREAS & & & & \\
R precentral gyrus & 6 & 115 & 52028 & 3.16 \\
PARIETAL AREAS & & & & \\
R postcentral gyrus & 3 & 132 & $50-1244$ & 3.05 \\
R postcentral gyrus & 3 & & $42-1846$ & 2.82 \\
\hline
\end{tabular}

$B A$, Brodmann's area; $R$, right.

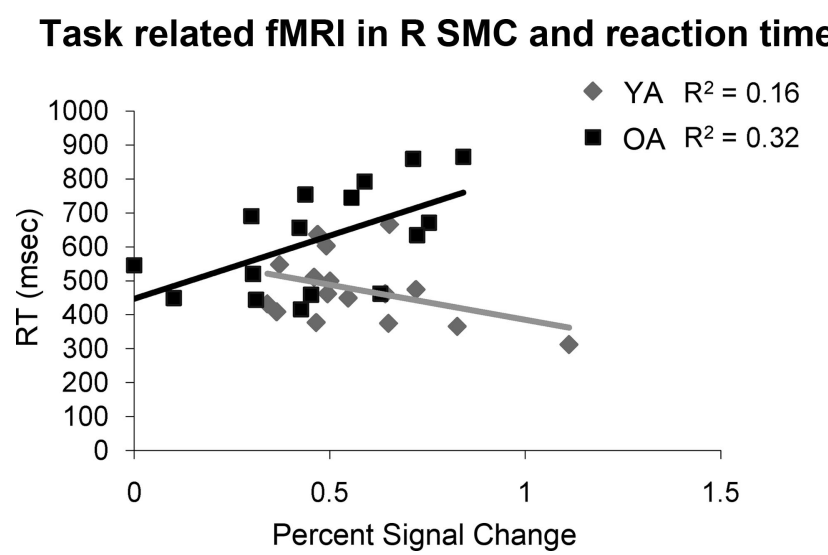

FIGURE 4 | Older adults (OA) demonstrate a significant positive correlation between reaction time and fMRI activation in the right sensorimotor cortex (R SMC) while young adults (YA) do not. 

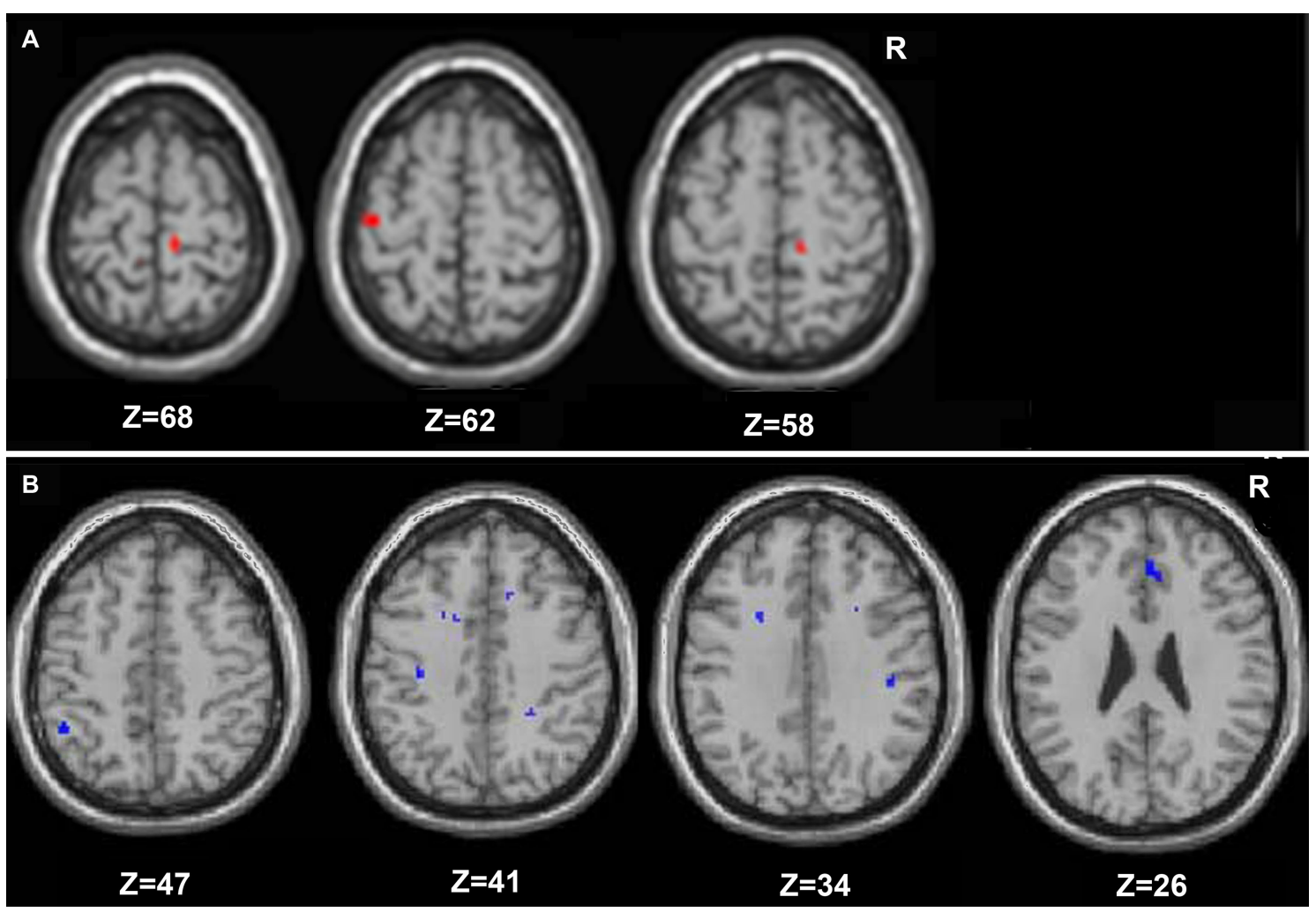

FIGURE 5 | Regions in which young adults exhibited greater resting functional connectivity than older adults are presented in (A), and areas in which the older adults had greater connectivity than the young are in (B) (whole brain analyses).

of sensorimotor cortex interhemispheric connectivity compared to young adults (Figures 6A,B, Table 4). Interestingly, older adults that display stronger sensorimotor cortex interhemispheric connectivity also demonstrate reduced percent signal change in the right sensorimotor cortex during the fMRI task $(\mathrm{df}=14, r=-0.52$, $p=0.04$, Figure 7).

\section{CORPUS CALLOSUM RESULTS}

Inter-rater reliability scores for both CC measurements and intracranial measurements were good (Krippendorff's alpha $=0.91$ and 0.89 respectively). The overall mid-sagittal cross-sectional area of the CC (normalized to intracranial area) was diminished in older adults compared to young adults $\left(t_{(32)}=2.28, p=0.03\right)$. In particular, regions thought to link the premotor and supplementary motor cortices such as the genu $\left(t_{(32)}=3.61, p<0.01\right)$, and primary motor cortices such as the intermediate truncus $\left(t_{(32)}=2.78\right.$, $p=0.01)$, posterior intermediate truncus $\left(t_{(32)}=2.23, p=0.03\right)$, and isthmus $\left(t_{(32)}=2.17, p=0.04\right)$ were smaller in older adults than young adults (Figures 8A,B). We hypothesized that older adults with reductions in these regions would demonstrate stronger interhemispheric communication between motor cortices, greater taskrelated fMRI activation in the right (ipsilateral) sensorimotor cortex and better performance. We found that older adults with smaller genu size had greater sensorimotor cortex interhemispheric connectivity (Figure 9, df $=14, r=-0.49, p=0.05$ ). In addition, older adults demonstrated a negative relationship between size of the anterior and posterior intermediate truncus and fMRI laterality index $(\mathrm{df}=12, r=-0.55, p=0.04$ and $\mathrm{df}=12, r=-0.57, p=0.03$ respectively). That is, older adults that had greater mid-sagittal area in the anterior and posterior intermediate truncus recruited the right sensorimotor cortex more during the motor task. While the young adults demonstrated similarities to the older adults in the relationship between CC genu area and interhemipheric connectivity, it did not reach statistical significance ( $\mathrm{df}=16, r=-0.42$, $p=0.10)$. No other CC region was correlated with the fMRI laterality index in young adults $(p>0.18)$.

\section{DISCUSSION}

The data supported our hypothesis that older adults would show decreased lateralization of M1 activity during motor task performance. These findings replicate the results of previous fMRI studies of the aging motor system (Mattay et al., 2002; Ward and Frackowiak, 2003; Riecker et al., 2006). We further hypothesized that greater activation during the fMRI task would be associated with better performance. Unlike previous research (Mattay et al., 2002), we found that OA with greater ipsilateral M1 activation had longer RTs.

These results demonstrate that additional activation in older adults is not universally compensatory. Similarly, Riecker et al. (2006) found that over-activation in older adults did not scale with increasing task difficulty, and interpreted this as a noncompensatory effect. The bulk of the work supporting the idea of compensatory over-recruitment relates to prefrontal activation and cognitive tasks (Reuter-Lorenz et al., 2000; Cabeza et al., 2002; 


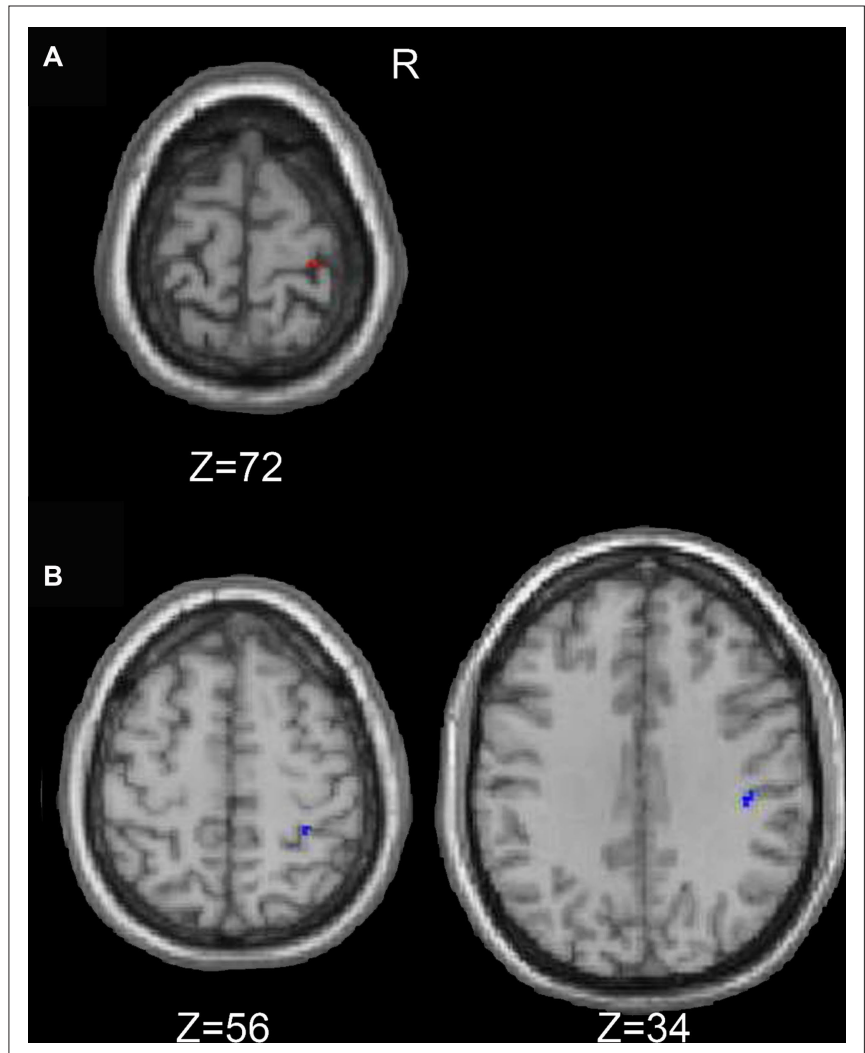

FIGURE 6 | Regions in which the young exhibited greater resting functional connectivity than the older adults are presented in (A), and areas in which the older adults had greater connectivity than the young adults are in (B) (right sensorimotor cortex ROI analyses).

Table 4 | Young adults (YA) versus older adults (OA) R sensorimotor cortex fcMRI (uncorrected $p=0.01$, right sensorimotor cortex ROI analyses).

Anatomical location BA Cluster size Coordinates of peaks z score

\begin{tabular}{|c|c|c|c|c|}
\hline \multicolumn{5}{|l|}{$\mathrm{YA}>\mathrm{OA}$} \\
\hline \multicolumn{5}{|l|}{ Parietal areas } \\
\hline R Postcentral gyrus & 1 & 9 & $28-2872$ & 3.24 \\
\hline \multicolumn{5}{|l|}{ OA $>$ YA } \\
\hline \multicolumn{5}{|l|}{ Frontal areas } \\
\hline R Precentral gyrus & 6 & 7 & 58230 & 2.92 \\
\hline \multicolumn{5}{|l|}{ Parietal areas } \\
\hline R Postcentral gyrus & 2 & 7 & $42-2434$ & 3.2 \\
\hline R Postcentral gyrus & 2 & 5 & $32-3856$ & 2.66 \\
\hline
\end{tabular}

BA, Brodmann's area; $R$, right.

Paxton et al., 2008). While over-activation of prefrontal regions may enhance cognitive task performance in older adults, increased activation in the ipsilateral M1 may be counterproductive to the performance of unimanual motor tasks. In young adults, movement of the dominant hand has an overall inhibitory effect on the ipsilateral M1 (Sohn et al., 2003). Indeed, such inhibitory processes factor strongly into the execution of precise unimanual movements. Motor evoked potentials induced through transcranial magnetic
Resting state connectivity and task related fmri in R SMC

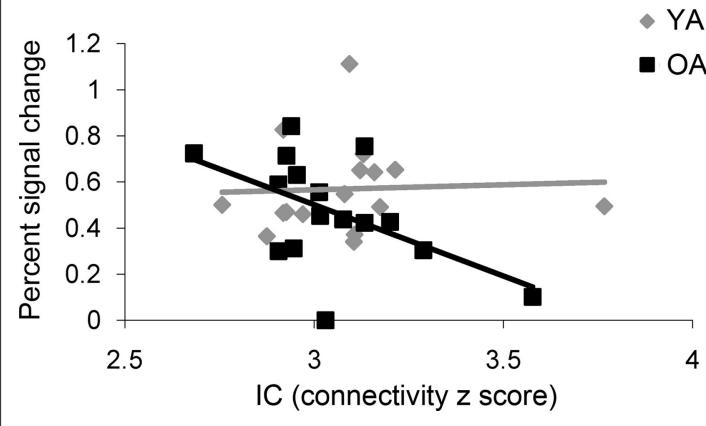

FIGURE 7 |The older adults (OA) had a negative correlation between resting functional connectivity strength in the right sensorimotor cortex (R SMC) ROI and fMRI activation in the same region, while the young adults (YA) did not.

stimulation (TMS) are greater in hand muscles used during a movement thus showing decreased inhibition. Meanwhile muscles that are not engaged to produce a movement show higher levels of inhibition (Liepert et al., 1998; Stinear and Byblow, 2002), a characteristic that would reduce unintended movements. Ipsilateral muscles assessed by motor evoked potentials also showed increased inhibition following simple movements (Leocani et al., 2000). This pattern of interhemispheric inhibition, coupled with our findings, suggests that older adults that maintain the ability to inhibit the ipsilateral M1 during movement are able to perform unimanual motor tasks more efficiently. Therefore, increased activation in older adults may have positive or negative consequences for task performance, depending on the role that the brain region plays in the task. This view is supported by previous research (Colcombe et al., 2005; Wierenga et al., 2008).

As predicted, older adults demonstrated greater resting connectivity compared to young adults in both the whole brain and right sensorimotor cortex ROI analyses. Taniwaki et al. (2007) used structural equation modeling to measure effective connectivity associated with motor task performance and also found increased interhemispheric connectivity between ventral premotor cortices, supplementary motor areas and sensorimotor cortex in older adults. In contrast, others have reported age-related decreases in functional connectivity (Wu et al., 2007; Taniwaki et al., 2007), particularly in the basal ganglia thalamocortical motor loop during a self initiated motor task in older adults. Combined, these data suggest that aging may have differential effects on subcorticalcortical and cortico-cortical connectivity. Increased connectivity in cortical regions throughout the brain may influence performance for older adults. In a study examining speech perception under conditions of decreased clarity of speech, stronger functional connectivity between cortical regions remote to the auditory cortex was associated with greater comprehension (Obleser et al., 2007). Age differences in connectivity throughout the brain are intriguing and deserve further research. However, here we focus our discussion on interhemispheric connectivity between sensorimotor cortices and the relationship to motor task-related activation and cross-sectional area of the CC. 


\section{${ }^{A}$ Area of Corpus Callosum Regions}

\section{${ }^{B}$ Area of Corpus Callosum}
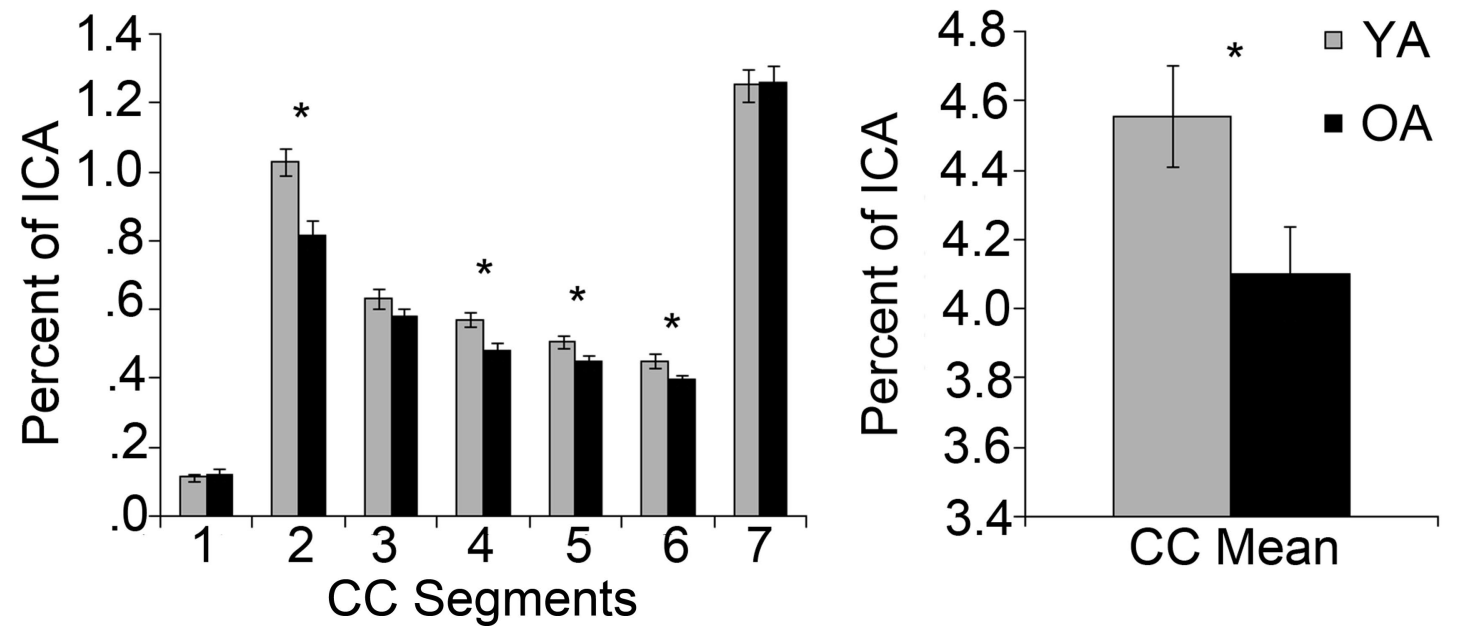

FIGURE 8 | (A) Normalized area of CC regions and standard error (SE) in young adults (YA) and older adults (OA). The CC is divided into seven regions: (1) rostrum, (2) genu, (3) rostral truncus, (4) anterior intermediate truncus,
(5) posterior intermediate truncus, (6) isthmus, (7) splenium. (B) Mean cross-sectional area of the entire CC and SE. Asterisk indicates significant group differences at $p<0.05$.

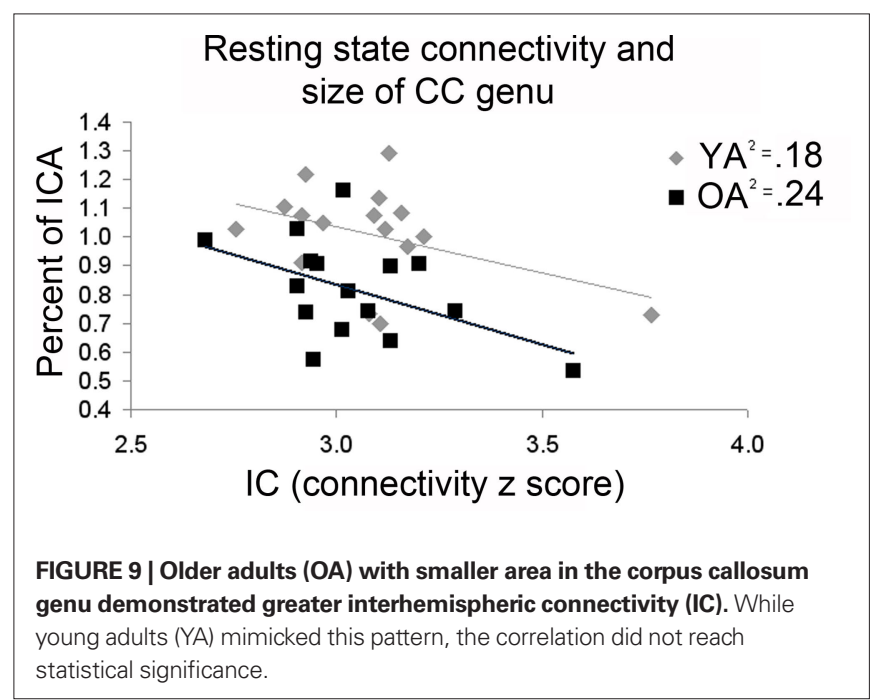

We hypothesized that older adults who demonstrate stronger resting state interhemispheric connectivity would exhibit less lateralized task-related motor cortical activity. Previous work suggests that age-related changes in the CC disrupt interhemispheric balance, resulting in disinhibition of the ipsilateral hemisphere (Talelli et al., 2008a,b). In the current study we found that older adults demonstrated both increased connectivity and decreased laterality of task-related motor cortical activation compared to the young adults. Interestingly, we found a negative correlation between sensorimotor cortex interhemispheric connectivity and task-related fMRI activation in the right sensorimotor cortex. This pattern suggests that older adults with greater interhemishperic connectivity more effectively inhibited the ipsilateral sensorimotor cortex. A study with young adults demonstrated similar findings using an encoding task (Putnam et al., 2008). During a verbal encoding task that is typically lateralized to the left prefrontal cortex, young adults with greater anterior callosal fractional anisotropy, a measurement of white matter integrity, activated the right prefrontal cortex less than young adults with lower fractional anisotropy. Young adults also demonstrated a negative correlation between encoding accuracy and right inferior prefrontal cortex activation (Putnam et al., 2008). Interhemispheric inhibition is believed to be mediated through excitatory neurons in the motor cortices that synapse onto local inhibitory networks (Chen, 2004). It may be that older adults with stronger connectivity better engage the local inhibitory networks, resulting in less ipsilateral activation during a task and better performance.

Integrity of the CC impacts movement efficacy. Prior to complete myelination of the CC, children display bilateral movements or muscle activation during tasks intended to be unilateral. This is known as motor overflow or in cases where there is overt movement, mirror movements (Addamo et al., 2007). On the other end of the age spectrum, older adults show a reduction in number and integrity of CC fibers (Sullivan et al., 2002; Head et al., 2004) potentially impacting connectivity and unimanual motor control. We found the size of the CC was diminished in older adults, specifically in the following regions: the genu, anterior and posterior intermediate truncus, and isthmus. Older adults with smaller genu regions showed greater sensorimotor cortex interhemispheric connectivity. Based on previous studies (Ota et al., 2006) demonstrating age-related degeneration of the CC and disruption of interhemispheric inhibition (Talelli et al., 2008a), we had predicted the CC would be diminished in older adults and sensorimotor cortex interhemispheric connectivity would be greater. However, we anticipated that these traits would lead to disinhibition in the ipsilateral hemisphere. Surprisingly, in our results there was a negative correlation between fMRI laterality index and the size of both the anterior and posterior intermediate truncus. These findings all point toward a reduction in right sensorimotor cortex activation with diminished size of these CC regions. 
This pattern of more lateralized activation in combination with diminished CC size has been noted in other studies. For example, behavioral measures of laterality for dichotic word listening, line bisection and turning bias are negatively correlated with callosal size (Yazgan et al., 1995). Movement-related potentials recorded through electroencephalography (EEG) are stronger on the ipsilateral side when the genu and intermediate truncus are larger (Stancak et al., 2000). Additionally, older adults demonstrating strong memory performance also display stronger fractional anisotropy in the CC genu and reduced activation in the right frontal gyrus (Persson et al., 2006). This relationship between CC size or integrity and interhemispheric interactions is likely to be nonlinear, though. While some degeneration of the CC may result in reduced interhemispheric inhibition and greater motor overflow, extensive damage or complete section of the CC would likely abolish or greatly diminish interhemispheric interactions.

Our findings support that age-related resting state physiological changes contribute to functional brain activation patterns and performance. This is important to note as task difficulty has been offered as an explanation for differences in brain activation patterns between older adults and young adults (Smith et al., 2001; Logan et al., 2002; Tisserand and Jolles, 2003). Our data disputes task difficulty as the sole explanation for alterations in brain activation patterns in older adults, because we note changes in motor network connectivity at rest. We found greater resting state interhemispheric connectivity in older adults compared to young adults, and a negative relationship between sensorimotor cortex interhemispheric connectivity and activation in the right sensorimotor cortex in older adults. Thus task difficulty may account for some but not all aspects of age differences in brain recruitment patterns.

It is possible that a stronger degree of right handedness in older adults (Porac, 1993; Dittmar, 2002), a phenomenon also noted in our study, may account for some of the differences we found between older adults and young adults. Environmental theories suggest that the world around us promotes use of the right hand and increased practice leads to more exclusive use of the right hand with aging (Harris, 1990). Since there is a connection between physical activity and brain function (Nudo et al., 1996), greater reliance on the right hand in older adults may influence connectivity and functional brain activation. With that stated, both the young and older adults in our study demonstrated right handedness with mean scores above 75 and only 12 points separating groups on a scale ranging from -100 (extreme left handedness) to +100 (extreme right handedness). While statistically significantly different there may be little practical difference between groups.

Understanding the relationships between neuroanatomy, neurophysiology, and behavioral function in typically aging adults is important as it may lead to better recommendations for healthy aging in this rapidly growing subpopulation. Also, by strengthening our knowledge of typical progression in aging there is the potential to better understand what goes awry in pathological conditions. This research may help to provide insight into pathologies that share characteristics with aging adults, such as multiple sclerosis, a pathology in which the integrity of white matter tracts is reduced due to demyelination. In a study investigating middle aged adults with multiple sclerosis, microstructural damage in the CC [measured through diffusion tensor imaging (DTI) using mean diffusivity value] was positively correlated with activation in ipsilateral M1 during a simple motor task (Lenzi et al., 2007). Interestingly, the same study found a negative correlation between M1 ipsilateral activation and duration of transcollosal inhibition. Moreover, longer inhibition durations in individuals with multiple sclerosis have been shown to be indicative of greater demyelination (Hoppner et al., 1999) and greater disability (Schmierer et al., 2002). This would suggest that deterioration of the $\mathrm{CC}$ is associated with greater inhibition of ipsilateral M1. It is clear that brain function, particularly in cases of pathology, are not straight forward (Pantano et al., 2006) and future studies are needed.

This research may also help to provide insight into pathologies that typically impact older adults. Gaining a greater understanding of interhemispheric interactions in healthy older adults is important in light of the role interhemispheric communication may play following stroke. For example, it has been shown that interhemispheric inhibition exerted by the intact hemisphere over the lesioned hemisphere may hinder recovery (Murase et al., 2004; Duque et al., 2005). During movements of the paretic hand there is increased interhemispheric inhibition targeting M1 in the lesioned hemisphere. Learning what role sensorimotor cortex interhemispheric connectivity plays in normal movement and understanding how exercise may alter function in the ipsilateral and contralateral M1 (Duque et al., 2007) may serve an important function in stroke rehabilitation.

One potential limitation of the current study is that we did not incorporate DTI metrics of callosal integrity. However, we felt that this was beyond the scope of the current investigation, particularly given the desire to limit magnet time to a reasonable duration for our older adult participants. Instead, we evaluated and integrated fMRI, structural MRI, and fcMRI metrics. Future research should further investigate the relationships between neuroanatomy and function using a tool such as DTI to better reflect white matter connections and microstructure of axons in the CC (Hagmann et al., 2003; Vernooij et al., 2008).

In conclusion, we found that older adults recruited the ipsilateral sensorimotor cortex to a greater extent during motor task performance than young adults. The cross-sectional area of the CC in older adults was diminished compared to young adults. Older adults with a smaller CC genu demonstrated stronger sensorimotor cortex interhemispheric connectivity. Interestingly, older adults with stronger sensorimotor cortex interhemispheric connectivity retained the ability to inhibit the ipsilateral sensorimotor cortex during a motor task. Furthermore we found that older adults that successfully inhibited the right sensorimotor cortex performed the motor task more proficiently, demonstrating that increased activation is not uniformly beneficial for older adults. The function of the region and the role it plays in the task may determine the relationship between over-activation and performance.

\section{ACKNOWLEDGMENTS}

Thanks to C. Amer, B. Downs, S. Durussel-Weston, S. Kaviany, A. Miller, A. Sandusky, D. Scott, and A. Stubbs for their assistance in this study. This work was supported by National Institutes of Health [grant numbers AG024106 (RS), T32-AG000114], and the UM National Institutes of Health Claude D. Pepper Center Human Subjects and Assessment Core (grant number AG024824). The authors declare that there are no actual or potential conflicts of interest. 


\section{REFERENCES}

Addamo, P. K., Farrow, M., Hoy, K. E., Bradshaw, J. L., and GeorgiouKaristianis, N. (2007). The effects of age and attention on motor overflow production - a review. Brain Res. Rev. 54, 189-204.

Bartels, C., Mertens, N., Hofer, S., Merboldt, K. D., Dietrich, J., Frahm, J., and Ehreneich, H. (2008). Callosal dysfunction in amyotrophic lateral sclerosis correlates with diffusion tensor imaging of the central motor system. Neuromuscul. Disord. 18, 398-407.

Biswal, B. B., Mennes, M., Zuo, X., Gohel, S., Kelly, C., Smith, S. M., Beckmann, C. F., Adelstein, J. S., Buckner, R. L., Colcombe, S., Dogonowski, A., Ernst, M., Fair, D., Hampson, M., Hoptman, M. J., Hyde, J. S., Kiviniemi, V. J., Kötter, R., Li, S., Lin, C., Lowe, M. J., Mackay, C., Madden, D. J., Madsen, K. H., Margulies, D. S., Mayberg, H. S., McMahon, K., Monk, C.S., Mostofsky, S. H., Nagel, B. J., Pekar, J. J., Peltier, S. J. Petersen, S. E., Riedl, V., Rombouts, S. A., Rypma, B., Schlaggar, B. L., Seidler, R. D., Siegle, G. J., Sorg, C., Teng, G., Veijola, J., Villringer, A., Walter, M., Wang, L., Weng, X., Whitfield-Gabrieli, S., Williamson, P., Windischberger, C., Zang, Y., Zhang, H., Castellanos, F. X., and Milham, M. P. (2010). Towards discovery science of human brain function. PNAS 107, 4734-4739.

Biswal, B., Yetkin, F. Z., Haughton, V. M., and Hyde, J.S. (1995). Functional connectivity in the motor cortex of resting human brain using echo-planar MRI. Magn. Reson. Med. 34, 537-541.

Cabeza, R.(2001). Cognitive neuroscience of aging: contributions of functional neuroimaging. Scand. J. Psychol. 42, 277-286.

Cabeza, R., Anderson, N. D., Locantore, J. K., and McIntosh, A. R. (2002). Aging gracefully: compensatory brain activity in high-performing older adults. Neuroimage 17, 1394-1402.

Chen, R. (2004). Interactions between inhibitory and excitatory circuits in the human motor cortex. Exp. Brain Res. 154, 1-10.

Colcombe, S. J., Kramer, A. F., Erickson, K. I., and Scalf, P. (2005). The implications of cortical recruitment and brain morphology for individual differences in inhibitory function in aging humans. Psychol. Aging 20, 363-375.

Cordes, D., Haughton, V. M., Arfanakis, K., Wendt, G. J., Turski, P. A., Moritz, C. H., Quigley, M. A., and Meyerand, M. E. (2000). Mapping functionally related regions of brain with functional connectivity MR imaging. Am. J. Neuroradiol. 21, 1636-1644.

De Gennaro, L., Cristiani, R., Bertini, M., Curcio, G., Ferrara, M., Fratello, F., Romei, V., and Rossini, P. M. (2004).
Handedness is mainly associated with an asymmetry of corticospinal excitability and not of transcallosal inhibition. Clin. Neurophysiol. 115, 1305-1312.

De Luca, M., Smith, S., De Stefano, N., Federico, A., and Matthews, P. M. (2005). Blood oxygenation level dependent contrast resting state networks are relevant to functional activity in the neocortical sensorimotor system. Exp. Brain Res. 167, 587-594.

Di Martino, A., Scheres, A., Margulies, D. S., Kelly, A. M., Uddin, L. Q., Shehzad, Z., Biswal, B., Walters, J. R., Castellanos, F. X., and Milham, M. P. (2008). Functional connectivity of human striatum: a resting state FMRI study. Cereb. Cortex 18, 2735-2747.

Dittmar, M. (2002). Functional and postural lateral preferences in humans: interrelations and life-span age differences. Human Biol. 74, 569-585.

Duque, J., Murase, N., Celnik, P.,Hummel, F., Harris-Love, M., Mazzocchio, R., Olivier, E., and Cohen, L. G. (2007). Intermanual differences in movementrelated interhemispheric inhibition.J. Cogn. Neurosci. 19, 204-213.

Duque, J., Hummel, F., Celnik, P., Murase, N., Mazzocchio, R., and Cohen, L. G. (2005). Transcallosal inhibition in chronic subcortical stroke. Neuroimage 28, 940-946.

Eccles, J. C. (1989). Evolution of the Brain: Creation of the Self. London: Routledge.

Fabri, M., Polonara, G., Quattrini, A., Salvolini, U., Del Pesce, M., and Manzoni, T. (1999). Role of the corpus callosum in the somatosensory activation of the ipsilateral cerebral cortex: an fMRI study of callosotomized patients. Eur. J. Neurosci. 11, 3983-3994.

Ferbert, A., Priori, A., Rothwell, J. C., Day, B. L., Colebatch, J. G., and Marsden, C. D. (1992). Interhemispheric inhibition of the human motor cortex. J. Phys. 453, 525-546.

Folstein, M. F., Folstein, S. E., and McHugh, P. R. (1975). "Mini-mental state” A practical method for grading the cognitive state of patients for the clinician. J. Psychiatr. Res. 12, 189-198.

Fox, M. D., and Raichle, M. E. (2007) Spontaneous fluctuations in brain activity observed with functional magnetic resonance imaging. Nat. Rev. Neurosci. 8, 700-711.

Glover, G.H., Li, T. Q., and Ress, D. (2000) Image-based method for retrospective correction of physiological motion effects in AMRI: RETROICOR. Magn. Reson. Med. 44, 162-167.

Hagmann, P., Thiran, J. P., Jonasson, L., Vandergheynst, P., Clarke. S., Maeder, P., and Meuli, R. (2003). DTI mapping of human brain connectivity: statistical fibre tracking and virtual dissection. Neuroimage 19, 545-554.
Harris, L. J. (1990). "Cultural influences on handedness: historical and contemporary theory and evidence," in LeftHandedness: Behavioral Implications and Anomalies, ed. S. Coren (Amsterdam, North-Holland: Elsevier) 195-258.

Hayes, A., and Krippendorff, K. (2007). Answering the call for a standard reliability measure for coding data. Commun. Methods Meas. 1, 77-89.

Head, D., Buckner, R. L., Shimony, J. S. Williams, L.E.,Akbudak, E., Conturo, T. E., McAvoy,M.,Morris, J.C., and Snyder, A.Z.(2004).Differential vulnerability of anterior white matter in nondemented aging with minimal acceleration in dementia of the Alzheimer type: evidence from diffusion tensor imaging Cereb. Cortex 14, 410-423.

Heuninckx, S., Wenderoth, N., Debaere, F, Peeters, R., and Swinnen, S. P. (2005) Neural basis of aging: the penetration of cognition into action control. J. Neurosci. 25, 6787-6796.

Heuninckx, S., Wenderoth, N., and Swinnen, S. P. (2008). Systems neuroplasticity in the aging brain: recruiting additional neural resources for successful motor performance in elderly persons. J. Neurosci. 28, 91-99.

Hofer, S., and Frahm, J. (2006) Topography of the human corpus callosum revisited-comprehensive fiber tractography using diffusion tensor magnetic resonance imaging. Neuroimage 32, 989-994.

Hoppner, J., Kunesch, E., Buchmann, J. Hess, A., Grossmann, A., and Benecke, R. (1999). Demyelination and axonal degeneration in corpus callosum assessed by analysis of transcallosally mediated inhibition in multiple sclerosis. Clin. Neurophysiol. 110, 748-756.

Hutchinson, S., Kobayashi, M., Horkan, C. M., Pascual-Leone, A., Alexander, M. P., and Schlaug, G. (2002). Age-related differences in movement representation. Neuroimage 17, 1720-1728.

Johnston, J. M., Vaishnavi, S. N., Smyth, M. D., Zhang, D. Y., He, B. J., Zempel, J. M., Shimony, J. S., Snyder, A. Z., and Raichle, M. E. (2008). Loss of resting interhemispheric functional connectivity after complete section of the corpus callosum. J. Neurosci. 28 , 6453-6458.

Lenzi, D., Conte, A., Mainero, C., Frasca, V., Fubelli, F., Totaro, P., Cararnia, F., Inghilleri, M., Pozzilli, C., and Pantano, P. (2007). Effect of corpus callosum damage on ipsilateral motor activation in patients with multiple sclerosis: a functional and anatomical study. Hum. Brain Mapp. 28, 636-644.

Leocani, L., Cohen, L. G., Wassermann, E. M., Ikoma, K., and Hallett, M. (2000). Human corticospinal excitability evaluated with transcrania magnetic stimulation during differ- ent reaction time paradigms. Brain $123,1161-1173$

Li, S. C., Lindenberger, U., and Sikstrom, S. (2001). Aging cognition: from neuromodulation to representation. Trends Cogn. Sci. (Regul. Ed.) 5, 479-486.

Li, S. C., and Sikstrom, S. (2002) Integrative neurocomputational perspectives on cognitive aging, neuromodulation, and representation. Neurosci. Biobehav. Rev. 26, 795-808.

Liepert, J., Classen, J., Cohen, L. G., and Hallett, M. (1998). Task-dependent changes of intracortical inhibition. Exp. Brain Res. 118, 421-426.

Logan, J. M., Sanders, A. L., Snyder, A. Z., Morris, J. C., and Buckner, R. L. (2002). Under-recruitment and nonselective recruitment: dissociable neural mechanisms associated with aging. Neuron 33, 827-840.

Lowe, M. J., Beall, E. B., Sakaie, K. E., Koenig, K. A., Stone, L., Marrie, R. A. and Phillips, M. D. (2008). Resting state sensorimotor functional connectivity in multiple sclerosis inversely correlates with transcallosal motor pathway transverse diffusivity. Hum. Brain Mapp. 29, 818-827.

Lowe, M. J., Mock, B. J., and Sorenson, J. A. (1998). Functional connectivity in single and multislice echoplanar imaging using resting-state fluctuations. NeuroImage 7, 119-132.

Madden,D.J., Turkington, T.G.,Provenzale, J.M., Denny, L. L., Hawk, T. C., Gottlob, L. R., and Coleman, R. E. (1999). Adult age differences in the functional neuroanatomy of verbal recognition memory. Hum. Brain Mapp. 7, 115-135.

Maldjian, J. A., Laurienti, P. J., Kraft, R. A., and Burdette, J. H. (2003). An automated method for neuroanatomic and cytoarchitectonic atlas-based interrogation of fMRI data sets. Neuroimage $19,1233-1239$.

Mattay, V. S., Fera, F., Tessitore, A., Hariri, A. R., Das, S., Callicott, J. H., and Weinberger, D. R. (2002). Neurophysiological correlates of agerelated changes in human motor function. Neurology 58, 630-635.

Mattis, S. (1976). "Mental status examination for organic mental syndrome in the elderly patient," in Geriatric Psychiatry, eds L. Bellak and T. B. Karasu (New York: Grune \& Stratton), 77-121.

Mazziotta, J.C., Toga, A. W., Evans, A., Fox, P., and Lancaster, J. (1995). A probabilistic atlas of the human brain - theory and rationale for its development. Neuroimage 2, 89-101.

Murase, N., Duque, J., Mazzocchio, R., and Cohen, L. G. (2004). Influence of interhemispheric interactions on motor function in chronic stroke. Ann. Neurol. 55, 400-409. 
Muller-Oehring,E.M.,Schulte, T., Raassi, C., Pfefferbaum, A., and Sullivan, E. V. (2007). Local-global interference is modulated by age, sex and anterior corpus callosum size. Brain Res. 1142, 189-205.

Netz, J. (1999). Asymmetry in transcallosal inhibition. Electroencephalogr. Clin. Neurophysiol. Suppl. 51, 137-144.

Nudo, R. J., Milliken, G. W., Jenkins, W. M., and Merzenich, M. M. (1996). Usedependent alterations of movement representations in primary motor cortex of adult squirrel monkeys. J. Neurosci. 16, 2, 785-807.

Obleser, J., Wise, R. J. S., Dresner, M. A., and Scott, S. K. (2007). Functional integration across brain regions improves speech perception under adverse listening conditions. J. Neurosci. 27, 2283-2289.

Oldfield, R. C. (1971). Assessment and analysis of handedness-Edinburgh inventory. Neuropsychologia 9, 97-113.

Ota, M., Obata, T., Akine, Y., Ito, H., Ikehira, H., Asada, T., and Suhara, T. (2006). Age-related degeneration of corpus callosum measured with diffusion tensor imaging. Neuroimage 31, 1445-1452.

Pantano, P., Mainero, C., and Caramia, F. (2006). Functional brain reorganization in multiple sclerosis: evidence from fMRI studies. J. Neuroimaging $16,104-114$.

Paxton, J. L., Barch, D. M., Racine, C. A., and Braver, T.S. (2008). Cognitive control, goal maintenance, and prefrontal function in healthy aging. Cereb. Cortex 18, 1010-1028.

Peltier, S. J., LaConte, S. M., Niyazov, D. M., Liu, J.Z., Sahgal, V., Yue, G. H., and $\mathrm{Hu}, \mathrm{X}$. P. (2005). Reductions in interhemispheric motor cortex functional connectivity after muscle fatigue. Brain Res. 1057, 10-16.

Persson, J., Nyberg, L., Lind, J., Larsson, A., Nilsson, L. G., Ingvar, M., and Buckner, R. L. (2006). Structure-function correlates of cognitive decline in aging. Cereb. Cortex 16, 907-915.

Porac, C. (1993).Areagetrendsin adulthand preference best explained by developmental shifts orgenerational-differences. Can. J. Exp. Psychol. Revue Canadienne De Psychologie Experimentale 47, 697-713.

Putnam, M. C., Wig, G. S., Grafton, S. T., Kelley, W. M., and Gazzaniga, M. S. (2008). Structural organization of the corpus callosum predicts the extent and impact of cortical activity in the nondominant hemisphere. J. Neurosci. 28, 2912-2918.

Quigley, M., Cordes, D., Turski, P., Moritz, C., Haughton, V., Seth, R., and Meyerand, M. E. (2003). Role of the corpus callosum in functional connectivity. Am. J. Neuroradiol. 24, 208-212.
Reuter-Lorenz, P.A.Jonides, J.,Smith, E. E., Hartley,A.,Miller,A., Marshuetz, C., and Koeppe, R. A. (2000). Age differences in the frontal lateralization of verbal and spatial working memory revealed by PET. J. Cogn. Neurosci. 12, 174-187.

Reuter-Lorenz, P.A., and Lustig, C. (2005). Brain aging: reorganizing discoveries about the aging mind. Curr. Opin. Neurobiol. 15, 245-251.

Riecker, A., Groschel, K., Ackermann, H., Steinbrink, C., Witte, O., and Kastrup A. (2006). Functional significance of agerelated differences in motor activation patterns. Neuroimage 32, 1345-1354.

Rogers, B. P., Morgan, V. L., Newton, A. T., and Gore, J. C. (2007). Assessing functional connectivity in the human brain by fMRI. Magn. Reson. Imaging $25,1347-1357$

Schmierer, K., Irlbacher, K., Grosse, P., Roricht, S., and Meyer, B. U. (2002). Correlates of disability in multiple sclerosis detected by transcranial magnetic stimulation. Neurology 59, 1218-1224.

Seidler, R. D., Bernard, J. A., Burutolu, T. B., Fling, B. W., Gordon, M. T., Gwin, J. T., Kwak, Y., and Lipps, D. B. (2010). Motor control and aging: links to agerelated brain structural, functional, and biochemical effects. Neurosci. Biobehav. Rev. 34, 721-733.

Seidler, R. D., Noll, D. C., and Thiers, G. (2004). Feedforward and feedback processes in motor control. Neuroimage 22, 1775-1783.

Smith, E. E., Geva, A., Jonides, J., Miller, A., Reuter-Lorenz, P., and Koeppe, R. A. (2001). The neural basis of taskswitching in working memory: effects of performance and aging. Proc. Natl. Acad. Sci. USA 98, 2095-2100.

Sohn, Y. H., Jung, H. Y., Kaelin-Lang, A., and Hallett, M. (2003). Excitability of the ipsilateral motor cortex during phasic voluntary hand movement. Exp. Brain Res. 148, 176-185.

Stancak, A., Lucking, C. H., and KristevaFeige, R. (2000). Lateralization of movement-related potentials and the size of corpus callosum. Neuroreport $11,329-332$.

Stancak, A., and C. H. Lucking, et al. (2002). The size of corpus callosum and functional connectivities of cortical regions in finger and shoulder movements. Brain Res. Cogn. Brain Res. 13, 61-74.

Stancak, A., Cohen, E., Seidler, R. D., Duong, T. Q., and Kim, S. (2003). The size of corpus callosum and the functional activation of motor cortical areas in bimanual and unimanual movements. Cereb. Cortex 13, 475-485.

Stancak, A., and J. Svoboda, et al. (2003b). Desynchronization of cortical rhythms following cutaneous stimulation: effects of stimulus repetition and intensity, and of the size of corpus callosurn. Clin. Neurophysiol. 114, 1936-1947.

Stinear, J. W., and Byblow, W. D. (2002). Disinhibition in the human motor cortex is enhanced by synchronous upper limb movements. J. Physiol. $543,307-316$.

Sullivan, E. V., Pfefferbaum, A., Adalsteinsson, E., Swan, G. E., and Carmelli, D. (2002). Differential rates of regional brain change in callosal and ventricular size: a 4-year longitudinal MRI study of elderly men. Cereb. Cortex 12, 438-445.

Talelli, P., Waddingham, W., Ewas, A., Rothwell, J.C., and Ward, N.S. (2008a). The effect of age on task-related modulation of interhemispheric balance. Exp. Brain Res. 186, 59-66.

Talelli, P., Ewas, A., Waddingham, W. Rothwell, J. C., and Ward, N. S. (2008b). Neural correlates of agerelated changes in cortical neurophysiology. Neuroimage 40, 1772-1781.

Taniwaki, T., Okayama, A., Yoshiura, T., Togao, O., Nakamura, Y., Yamasaki, T., Ogata, K., Shigeto, H., Ohyagi, Y., Kira, J., and Tobimatsu, S. (2007). Agerelated alterations of the functional interactions within the basal ganglia and cerebellar motor loops in vivo. Neuroimage 36, 1263-1276.

Teasdale, N., Bard, C., Fleury, M., Young, D. E., and Proteau, L. (1993). Determining movement onsets from temporal series. J. Mot. Behav. 25, 97-106.

Tisserand, D. J., and Jolles, J. (2003). On the involvement of prefrontal networks in cognitive ageing. Cortex 39 , 1107-1128.

Vercauteren, K., Pleysier, T., Van Belle, L., Swinnen, S. P., and Wenderoth, N. (2008). Unimanual muscle activation increases interhemispheric inhibition from the active to the resting hemisphere. Neurosci. Letters 445, 209-213. Vernooii, M.W., de Groot, M., van der Lugt, A., Ikram, M.A., Krestin, G.P., Hofman, A., Niessen, W. J., and Breteler, M. M B. (2008). White matter atrophy and lesion formation explain the loss of structural integrity of white matter in aging. Neuroimage 43, 470-477.

Verstynen, T., Diedrichsen, J., Albert, N., Aparicio, P., and Ivry, R. B. (2005). Ipsilateral motor cortex activity during unimanual hand movements relates to task complexity. J. Neurophysiol. 93 , 1209-1222.

Vincent, J. L., Patel, G. H., Fox, M. D., Snyder, A. Z., Baker, J. T., Van Essen, D. C., Zempel, J. M., Snyder, L. H. Corbetta, M., and Raichle, M. E. (2007). Intrinsic functional architecture in the anaesthetized monkey brain. Nature 447, 83-86.

Wahl, M., Lauterbach-Soon, B., Hattingen, E., Jung, P., Singer, O., Volz, S., Klein, J. C., Steinmetz, H., and Ziemann,
U. (2007). Human motor corpus callosum: topography, somatotopy, and link between microstructure and function. J. Neurosci. 27, 12132-12138.

Ward, N. S., and Frackowiak, R. S. J. (2003). Age-related changes in the neural correlates of motor performance. Brain 126, 873-888.

Wierenga, C.E., Benjamin, M., Gopinath, K., Perlstein, W. M., Leonard, C. M., Rothi, L. J. G., Conway, T., Cato, M. A., Briggs, R., and Crosson, B. (2008). Age-related changes in word retrieval: role of bilateral frontal and subcortical networks. Neurobiol. Aging 29, 436-451.

Winter, D. A. (1990). Biomechanics and Motor Control of Human Movements. New York: John Wiley \& Sons.

Witelson, S. F. (1989). Hand and sex differences in the isthmus and genu of the human corpus callosum. Brain 112, 799-835.

Wu, T., Zang, Y. F., Wang, L., Long, X. Y., Hallett, M., Chen, Y., Li, K. C., and Chan, P. (2007). Aging influence on functional connectivity of the motor network in the resting state. Neurosci. Lett. 422, 164-168.

Xiong, J.H., Parsons, L. M., Gao, J.H., and Fox, P.T. (1999). Interregional connectivity to primary motor cortex revealed using MRI resting state images. Hum. Brain Mapp. 8, 151-156.

Yazgan, M. Y., Wexler, B. E., Kinsbourne, M., Peterson, B., and Leckman, J. F. (1995). Functional-significance of individual variations in callosal area. Neuropsychologia 33, 769-779.

Yousry, T. A., Schmid, U. D., Alkadhi, H., Schmidt, D., Peraud, A., Buettner, A. and Winkler, P. (1997). Localization of the motor hand area to a knob on the precentral gyrus - a new landmark. Brain 120, 141-157.

Conflict of Interest Statement: The authors declare that the research was conducted in the absence of any commercial or financial relationships that could be construed as a potential conflict of interest.

Received: 14 December 2009; paperpending published: 09 February 2010; accepted: 11 May 2010; published online: 07 June 2010. Citation: Langan J, Peltier SJ, Bo J, Fling BW, Welsh RC and Seidler RD (2010) Functional implications of age differences in motor system connectivity. Front. Syst. Neurosci. 4:17. doi: 10.3389/ fnsys.2010.00017

Copyright (C) 2010 Langan, Peltier, Bo, Fling, Welsh and Seidler. This is an openaccess article subject to an exclusive license agreement between the authors and the Frontiers Research Foundation, which permits unrestricted use, distribution, and reproduction in any medium, provided the original authors and source are credited. 